\title{
Superoxide Dismutases in Polymorphonuclear Leukocytes
}

\author{
Marvin L. Salin and Joe M. McCord \\ From the Departments of Medicine and Biochemistry, Duke University Medical Center, \\ Durham, North Carolina 27710
}

\begin{abstract}
A B S T R A C T Isolated human polymorphonuclear leukocytes were found to contain two distinct superoxide dismutases, electrophoretically identical to the superoxide dismutases found in other human tissues. One is inhibited by cyanide and is located in the cytosol. The other is not inhibited by cyanide and is mitochondrial. These findings disagree with reports by other laboratories, which did not find the cyanide-sensitive cytoplasmic enzyme. The superoxide dismutase-containing preparation of leukocytes released large amounts of superoxide into the medium when the cells were phagocytizing, suggesting that, if the cell population is homogeneous, superoxide production probably takes place on the outer surface of the cell membrane, in addition to inside the phagocytic vacuole.
\end{abstract}

\section{INTRODUCTION}

Prokaryotic organisms possess a manganese-containing superoxide dismutase (1). Eukaryotic organisms contain two distinct types of superoxide dismutases: a copper and zinc-containing cytoplasmic enzyme (2) and a manganese-containing mitochondrial enzyme (3). Both superoxide dismutases catalyze the same reaction,

$$
\mathrm{O}_{2}^{-}+\mathrm{O}_{2}^{-}+2 \mathrm{H}^{+} \rightarrow \mathrm{H}_{2} \mathrm{O}_{2}+\mathrm{O}_{2},
$$

and serve to protect the organism from the reactive superoxide free radical, a common product of aerobic metabolism (4). The cuprozinc enzymes are inhibited by cyanide, whereas the manganoenzymes are not (5, 6).

DeChatelet, McCall, McPhail, and Johnston reported that human peripheral polymorphonuclear leukocytes contain only a cyanide-insensitive superoxide dismutase (presumably the manganoenzyme), which is located in the cytosol (7). More recently, Johnston and DeChatelet revised their assessment of the superoxide dismutase content of neutrophils, reporting that both

Received for publication 10 May 1974 and in revised form 3 July 1974. cyanide-sensitive and insensitive enzymes are present (8). An earlier study by Beckman, Lungren, and Tarnvik reported that polymorphonuclear leukocytes contained only the mitochondrial type of enzyme (9). These reports are contradictory, and two represent rather dramatic departures from the consistent picture established thus far by the many varied tissue sources examined as to enzyme type and intracellular localization. Therefore, it was thought worthwhile to investigate the situation once more. We find polymorphonuclear leukocytes to contain the same types of enzyme in the same intracellular locations as all the other eukaryotic tissue sources examined.

The question of the occurrence of superoxide dismutases in leukocytes has become particularly interesting in view of the finding by Babior, Kipnes, and Curnutte that phagocytizing leukocytes produce superoxide and release it into the suspending medium (10). Additional evidence suggests that superoxide production may be necessary for bactericidal action by leukocytes $(11,12)$. Thus, it appears that these specialized cells purposely produce the reactive $\mathrm{O}_{2}^{-}$and put the normally detrimental radical to good use.

\section{METHODS}

Isolation of cells. All procedures employed plastic or siliconized glass containers. Venous blood was drawn from human volunteers into heparinized syringes. The blood was diluted fourfold with $0.9 \%$ saline and, following the procedure of Boyum (13), the monocytes were isolated in a Ficoll-Hypaque gradient. The pellet containing the erythrocytes and polymorphonuclear leukocytes was brought to the original volume with $0.9 \%$ saline, then an equal volume of 3\% dextran (Sigma Chemical Co., St. Louis, Mo., average mol wt 500,000 ) in $0.9 \%$ saline was added. After 20 min of sedimentation under gravity, the supernate was withdrawn and centrifuged at $120 \mathrm{~g}$ for $10 \mathrm{~min}$. The pellet containing polymorphonuclear leukocytes was freed of contaminating erythrocytes by suspension in $10 \mathrm{ml}$ of $0.2 \%$ saline followed $30 \mathrm{~s}$ later by the addition of $10 \mathrm{ml}$ of $1.6 \%$ saline and centrifugation at $120 \mathrm{~g}$. This hypotonic lysis of erythrocytes was repeated until the pellet was visibly free of erythrocytes. The leukocyte pellet was then suspended

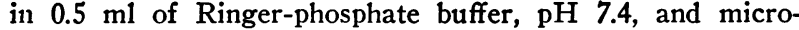


scopically examined. Cell viability, as judged by ability to exclude trypan blue, was greater than $98 \%$. The cells were greater than $98 \%$ polymorphonuclear leukocytes with less than one platelet per four leukocytes.

For purposes of comparative electrophoresis, a suspension of purified human platelets was generously provided by $\mathrm{Dr}$. P. A. McKee

Polyacrylamide disk gel electrophoresis. The procedure of Davis (14) was used with $10 \%$ acrylamide resolving gels. The activity staining procedure described by Beauchamp and Fridovich (15) was modified as follows: gels were soaked in individual tubes in the dark for $40 \mathrm{~min}$ in a single solution containing $50 \mathrm{mM}$ potassium phosphate, $\mathrm{pH} 7.8,1 \mathrm{mM}$ EDTA, $0.25 \mathrm{mM}$ nitroblue tetrazolium (Sigma Chemical Co.), $20 \mathrm{mM}$ tetramethylethylenediamine (Eastman Kodak Co., Rochester, N. Y.), and $30 \mu \mathrm{M}$ riboflavin (Sigma Chemical Co.). Where indicated, the staining solution also contained $1 \mathrm{mM}$ potassium cyanide. The solution was prepared in subdued light immediately before use. After the soaking period, the gels were removed from the solution and exposed to an incandescent desk lamp for about $20 \mathrm{~min}$. The photogenerated $\mathrm{O}_{2}^{-}$reduced the dye to the insoluble purple formazan except at those areas where superoxide dismutase scavenged the radical, resulting in achromatic bands.

Human liver, electrophoresed for comparison to leukocytes, was obtained from autopsy at Duke University Medical Center. Approximately $2 \mathrm{~g}$ of tissue was homogenized at $4^{\circ} \mathrm{C}$ in $40 \mathrm{ml}$ of Ringer-phosphate buffer in a Sorvall Omni-Mixer (Ivan Sorvall, Inc., Newtown, Conn.), then centrifuged at $5,000 \mathrm{~g}$ for $10 \mathrm{~min}$. The supernate was used for electrophoresis.

Subcellular fractionation of leukocytes. Leukocytes in Ringer-phosphate buffer $\left(2 \times 10^{8}\right.$ cells $\left./ \mathrm{ml}\right)$ were lysed by 20 strokes of a Potter-Elvejhem homogenizer, and centrifuged $10 \mathrm{~min}$ at $200 \mathrm{~g}$ to remove unbroken cells. The supernate was then centrifuged at $20,000 \mathrm{~g}$ for $30 \mathrm{~min}$. The resulting pellet was resuspended and treated with $0.2 \%$ Triton X-100 to lyse the mitochondria. Both the supernatant and solubilized pellet fractions were assayed for content of cyanide-sensitive and cyanide-insensitive superoxide dismutases.

Superoxide dismutase assays. Superoxide dismutase was spectrophotometrically assayed by modifications of the assay originally described in which the enzyme is detected by its ability to inhibit the superoxide-mediated reduction of ferricytochrome $c$ by xanthine oxidase plus xanthine (2). Xanthine oxidase, Grade I, and horse heart cytochrome $c$, Type III, were obtained from Sigma Chemical Co. Assays were routinely performed at $25^{\circ} \mathrm{C}$ in $20 \mathrm{mM}$ sodium carbonate buffer, $\mathrm{pH} 10$, containing $0.1 \mathrm{mM}$ EDTA. The assay for cuprozinc superoxide dismutase is 17 times as sensitive at $\mathrm{pH} 10$ as at $\mathrm{pH} 7.8$, although sensitivity for the manganoenzyme is not so markedly enhanced (5). Cytochrome $c$ reduction was monitored at $418 \mathrm{~nm}$, where the difference in molar extinction coefficients between the reduced and oxidized forms was found to be 70,000, as compared to a difference of 20,000 at $550 \mathrm{~nm}$. Since superoxide dismutase and cytochrome $c$ are in direct competition for the superoxide generated in the assay solution, the sensitivity of the assay increases as the cytochrome concentration decreases. Depending on the sensitivity required, the concentration of ferricytochrome $c$ in the assay was varied from $10 \mu \mathrm{M}$ to as low as $0.5 \mu \mathrm{M}$. For any given set of conditions, a calibration curve was obtained by using purified bovine erythrocyte superoxide dismutase as a standard (2).
Reaction mixtures were monitored with a GCA/McPherson model 707 spectrophotometer (McPherson Instrument Corp., Acton, Mass.), with full scale expanded to $0.1,0.05$, or 0.02 absorbance units. With all parameters optimized for sensitivity, as little as $0.2 \mathrm{ng}$ of cuprozinc enzyme could be measured with confidence in a $1-\mathrm{ml}$ reaction mixture. Manganoenzyme was measured with $1 \mathrm{mM}$ cyanide added to the reaction mixture to inhibit any cuprozinc enzyme present (5). Total superoxide dismutase was measured without cyanide. Cuprozinc enzyme was calculated from the difference between the two assays. Approximately $10^{5}$ cells contained sufficient superoxide dismutase for a single assay of sonicated leukocyte suspension. Assays of the subcellular fractions in the presence of cyanide required in excess of $10^{8}$ cells per assay.

Superoxide production by leukocytes. Freshly prepared leukocytes were induced to phagocytize by incubating the cells at $10^{7}$ cells $/ \mathrm{ml}$ in Ringer-phosphate buffer containing $5 \%$ human serum in the presence of Escherichia coli at a bacteria to leukocyte ratio of $5: 1$. The incubation was at $37^{\circ} \mathrm{C}$. The bacteria had been frozen, thawed, and washed twice with deionized water. To detect the release of superoxide into the medium, ferricytochrome $c$ was added at a concentration of $0.1 \mathrm{mM}$. To determine what fraction of the cytochrome $c$ reduction was superoxide mediated, a control reaction mixture contained, in addition, $100 \mu \mathrm{g}$ bovine superoxide dismutase. At timed intervals, $0.1-\mathrm{ml}$ aliquots were removed, diluted 10 -fold with buffer and centrifuged at 5,000 $g$ for $10 \mathrm{~min}$. The supernate was removed and its absorbance at $550 \mathrm{~nm}$ recorded. The cytochrome $c$ in each sample was then fully reduced by the addition of a few crystals of sodium dithionite, and the difference between the two readings was used to calculate the amount of ferricytochrome $c$ remaining and the amount of reduction that had occurred.

\section{RESULTS}

The results of activity-stained disk gel electrophoresis of sonicated human polymorphonuclear leukocytes, with homogenized human liver for comparison, are shown in Fig. 1. The cyanide-sensitive and cyanide-insensitive bands are electrophoretically identical for the two preparations. Identical results were likewise observed with human placenta, lung, and pancreas homogenates. Platelet contamination of the leukocyte preparation was low, and although platelets do contain superoxide dismutase, we ascertained by electrophoresis of purified platelets that the contribution of platelet superoxide dismutase would be quantitatively insignificant. Quantitative cuvette assays of the sonicated leukocyte preparation showed they contained an average of $5 \times 10^{-15} \mathrm{~g}$ of superoxide dismutase per cell, based on specific activities of the purified human cytoplasmic (2) and mitochondrial enzymes. ${ }^{1}$ About $65 \%$ of the activity was inhibited by cyanide. The total amount of activity is about half the amount contained in the average red cell, despite the considerably larger size of the leukocyte. The results of the subcellular fractionation of leukocytes indicate that the distribution of the two superoxide dismutases follows the precedent set by

\footnotetext{
${ }^{1} \mathrm{~J}$. Boyle, L. Rizzolo, and J. McCord. To be published.
} 


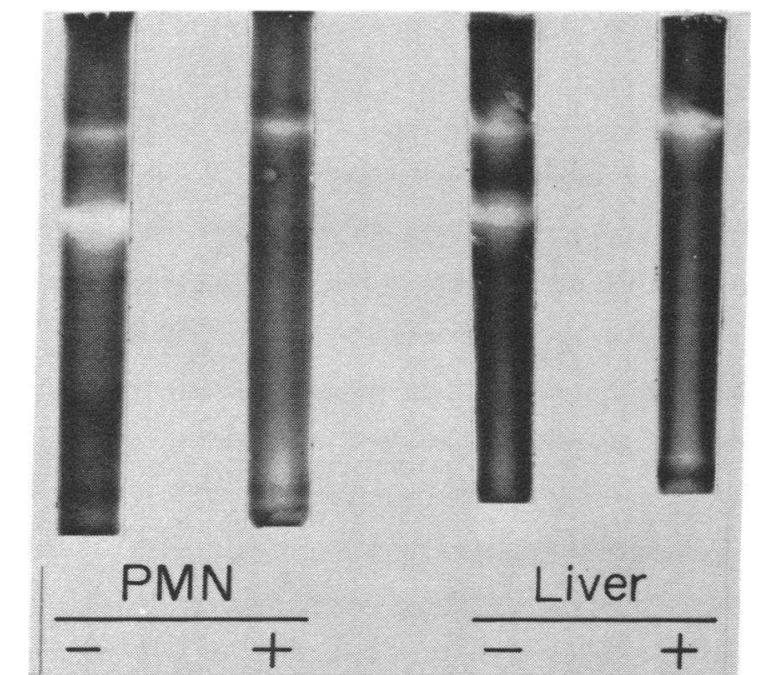

FIGURE 1 Results of polyacrylamide gel electrophoresis stained for superoxide dismutase activity. Electrophoresis and staining procedures were performed as described under Methods. Gels labeled $P M N$ received $30 \mu \mathrm{l}$ of a sonicated suspension of human polymorphonuclear leukocytes containing $10^{8}$ cells $/ \mathrm{ml}$. Gels labeled Liver received $5 \mu 1$ of the human liver preparation described under Methods. The gels designated + were stained in the presence of $1 \mathrm{mM}$ potassium cyanide.

other tissues $(3,5,9)$. The cytosol fraction $(20,000 \mathrm{~g}$ supernate) contained 1.7 times as much cuprozinc (cyanide-sensitive) enzyme as manganoenzyme (cyanideinsensitive), whereas the particulate fraction which would contain the mitochondria and granules $(20,000 \mathrm{~g}$ pellet) contained 1.4 times as much manganoenzyme as cuprozinc enzyme. These results are based on specific activities of the two types of enzyme at $\mathrm{pH} 10$ (5). Considerable cross-contamination is evident, but this is probably due to the technical difficulties met in breaking and fractionating the small amounts of cells.

The reports that polymorphonuclear leukocytes do not contain cytoplasmic superoxide dismutase (9) and that phagocytizing leukocytes produce and release superoxide (10) appeared in the literature at approximately the same time and seemed quite compatible. The most reasonable explanation seemed to be that if the cells had no cytoplasmic scavenging system, any superoxide produced in the cytosol by the various reactions of aerobic metabolism might well survive long enough to diffuse through the cell membrane and into the medium. Our present finding that leukocytes do indeed possess a cytoplasmic superoxide dismutase makes this hypothesis less attractive. One explanation for the discrepancy might be that since all the laboratories involved used different methods for isolating leukocytes, perhaps two different populations of leukocytes were being studied. That is, some cells may lack cytoplasmic enzyme and therefore release superoxide, while other morphologically similar cells may possess the cytoplasmic enzyme and therefore would not release any cytoplasmically generated superoxide. It was obviously important to determine if our superoxide dismutasecontaining preparation of cells was capable of releasing $\mathrm{O}_{2}^{-}$into the medium when the cells were phagocytizing. The results of an experiment to answer this question are shown in Fig. 2. Superoxide production was measured by the rate of superoxide dismutase-inhibitable cytochrome $c$ reduction taking place in the suspending medium. E. coli were used to stimulate phagocytosis. The cells produced $\mathrm{O}_{2}^{-}$at a rate of $1 \mathrm{~nm} / \mathrm{min} / 10^{7}$ cells. This rate is 15 times the rate originally reported when latex particles were used to stimulate phagocytosis (10), but is comparable to more recent observations which also used bacteria to stimulate the cells (12). If our preparation represents a single homogenous population of leukocytes, then cells which contain cytoplasmic superoxide dismutase do release $\mathrm{O}_{2}^{-}$into the medium when phagocytizing. It is also possible, however, that our preparation contains the two hypothetical populations of cells, some of which contain cytosolic superoxide dismutase and release no $\mathrm{O}_{2}^{-}$, others of which contain no cytosolic dismutase and do release $\mathrm{O}_{2}^{-}$. At present, we cannot conclude which situation exists.

One further possibility was considered which might lead to two populations of leukocytes of differing superoxide dismutase content. It is established that phago-

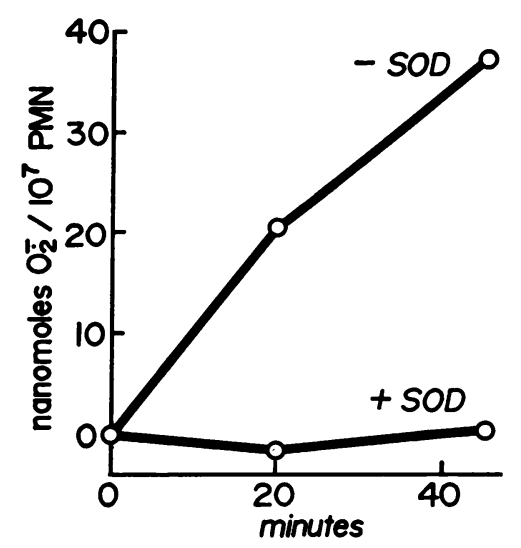

FIGURE 2 Superoxide production by human polymorphonuclear leukocytes. Each of the two reaction mixtures con-

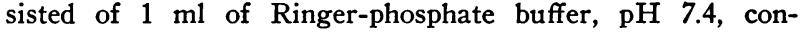
taining 5\% autologous serum, plus $10^{7}$ freshly prepared human leukocytes, $5 \times 10^{7} \mathrm{E}$. coli, and $0.1 \mathrm{mM}$ ferricytochrome $c$. The reaction mixture labeled $+S O D$ received in addition $100 \mu \mathrm{g}$ bovine superoxide dismutase. The ordinate represents superoxide detectable in the medium by virtue of cytochrome $c$ reduction. 
cytizing leukocytes produce hydrogen peroxide in appreciable quantities (16) and that hydrogen peroxide inactivates the cuprozinc dismutase at concentrations of $0.1 \mathrm{mM}$ or less $(5,6)$. Therefore, once a leukocyte is metabolically activated, as a certain fraction of peripheral leukocytes are at any given time, one might expect to see the cytoplasmic enzyme activity rapidly decrease due to inactivation by peroxide. To test this hypothesis, a preparation of leukocytes was induced to phagocytize $E$. coli under conditions similar to those described in Fig. 2, except that no cytochrome $c$ was present. At 30 -min intervals, aliquots of the incubation mixture were treated with $0.2 \%$ Triton $\mathrm{X}-100$ to release the leukocyte superoxide dismutase and centrifuged. The supernates were assayed for cyanide-sensitive and cyanide-insensitive superoxide dismutase activity. No decrease in either activity was observable after $2 \mathrm{~h}$, relative to the aliquot taken at zero time. We conclude that hydrogen peroxide concentration in the cytosol of phagocytizing leukocytes never reaches levels high enough to cause inactivation of the cuprozinc enzyme, or that the time required for such inactivation is longer than our period of observation.

\section{DISCUSSION}

The hypothesis that all oxygen-metabolizing cells must possess superoxide dismutase in order to survive in the presence of oxygen $(4,17)$ seems to be supported by the present findings. From the published findings of Beckman et al. (9) it appeared that polymorphonuclear leukocytes might represent an exception to the rule, but an exception with purpose. A prime objective of the phagocyte is to kill bacteria. Superoxide, probably via generation of $\mathrm{OH}$ - secondarily, is bactericidal (18) and leukocytes which cannot produce the radical cannot kill bacteria (12). Thus, if a leukocyte generated $\mathrm{O}_{2}^{-}$ in its cytoplasm by normal aerobic reactions but had no cytoplasmic scavenging system, one might expect that a bacterium held in a phagocytic vacuole might be exposed to a lethal amount of superoxide. One might also expect the leukocyte to be killed more quickly than the bacterium, which is not the case. Our finding of superoxide dismutases in leukocytes consistent in type and subcellular localization with all other tissues examined necessitates a refinement of this killing hypothesis. If cytoplasmic superoxide dismutase exists in the leukocyte, the $\mathrm{O}_{2}^{-}$produced for bactericidal purposes and detectable in the medium could not be generated in the cytoplasm, but must be generated outside the cytoplasm, either specifically in the phagocytic vacuole, or on the outer surface of the cell membrane, which invaginates to line the phagocytic vacuole. Since large amounts of superoxide are released from phago- cytically activated leukocytes, we suggest that the site of production includes the outer surface of the cell membrane, in part or in toto. Granulocyte 5'-nucleotidase has recently been shown to be located in such a manner on the outer surface of the membrane (19).

Whether the bactericidal mechanism hypothesized above is a physiological reality remains to be proven. The relative merits of this scheme as an alternative or additional killing mechanism to the proposed hydrogen peroxide-myeloperoxidase-halide mechanism (20) likewise remain to be seen.

\section{ACKNOWLEDGMENTS}

This work was supported by U. S. Public Health Service grants AM 17091 and AM 12413.

\section{REFERENCES}

1. Keele, B. B., Jr., J. M. McCord, and I. Fridovich. 1970. Superoxide dismutase from Escherichia coli $B$. A new manganese-containing enzyme. J. Biol. Chem. 245: 6176-6181.

2. McCord, J. M., and I. Fridovich. 1969. Superoxide dismutase. An enzymic function for erythrocuprein. J. Biol. Chem. 244 : 6049-6055.

3. Weisiger, R. A., and I. Fridovich. 1973. Superoxide dismutase: organelle specificity. J. Biol. Chem. 248: 3582-3592.

4. McCord, J. M., B. B. Keele, Jr., and I. Fridovich. 1971. An enzyme-based theory of obligate anaerobiosis: the physiological function of superoxide dismutase. Proc. Natl. Acad. Sci. U. S. A. 68: 1024-1027.

5. Beauchamp, C. O., and I. Fridovich. 1973. Isozymes of superoxide dismutase from wheat germ. Biochim. Biophys. Acta. 317: 50-64.

6. Bray, R. C., S. A. Cockle, E. M. Fielden, P. B. Roberts, G. Rotilio, and L. Calabrese. 1974. Reduction and inactivation of superoxide dismutase by hydrogen peroxide. Biochem. J. 139: 43-48.

7. DeChatelet, L. R., C. E. McCall, L. C. McPhail, and R. B. Johnston, Jr. 1974. Superoxide dismutase activity in leukocytes. J. Clin. Invest. 53: 1197-1201.

8. Johnston, R. B., Jr., and L. R. DeChatelet. 1974. Protection against superoxide anion. N. Engl. J. Med. $290: 1383$.

9. Beckman, G., E. Lundgren, and A. Tarnvik. 1973. Superoxide dismutase isozymes in different human tissues, their genetic control and intracellular localization. Hum. Hered. 23 : 338-345.

10. Babior, B., R. S. Kipnes, and J. T. Curnutte. 1973. The production by leukocytes of superoxide, a potential bactericidal agent. J. Clin. Invest. 52: 741-744.

11. Fridovich, I. 1974. Superoxide radical and the bactericidal action of phagocytes. N. Engl. J. Med. 290: 624 625.

12. Curnette, J. T., D. M. Whitten, and B. M. Babior. 1974. Defective superoxide production by granulocytes from patients with chronic granulomatous disease. $N$. Engl. J. Med. 290: 593-597.

13. Boyum, A. 1967. Isolation of mononuclear cells and granulocytes from human blood. Isolation of mononu- 
clear cells by one centrifugation and of granulocytes by combining centrifugation and sedimentation at $1 \mathrm{~g}$. Scand. J. Clin. Lab. Invest. 21 (Suppl. 97) : 77-89.

14. Davis, B. J. 1964. Disc electrophoresis II. Method and application to human serum proteins. Ann. N. Y. Acad. Sci. 121 : 404-427.

15. Beauchamp, C., and I. Fridovich. 1971. Superoxide dismutase: improved assays and an assay applicable to acrylamide gels. Anal. Biochem. 44 : 276-287.

16. Iyer, G. Y. N., D. F. Islam, and J. H. Quastel. 1961. Biochemical aspects of phagocytosis. Nature (Lond.). 192 : $535-541$.

17. McCord, J. M., C. O. Beauchamp, S. Goscin, H. Misra, and I. Fridovich. 1973. Superoxide and superoxide dismutase. In Oxidases and Related Redox Systems. T. E. King, H. S. Mason, and M. Morrison, editors. University Park Press, Baltimore, Md. Vol. 1. 51-76.

18. Gregory, E. M., F. J. Yost, Jr., and I. Fridovich. 1973. Superoxide dismutases of Escherichia coli: intracellular localization and functions. J. Bacteriol. 115: 987-991.

19. DePierre, J. W., and M. L. Karnovsky. 1974. Ectoenzyme of granulocytes: 5'-nucleotidase. Science (Wash. D. C.). 183: 1096-1098.

20. Karnovsky, M. L. 1973. Chronic granulomatous disease - pieces of a cellular and molecular puzzle. Fed. Proc. 32: 1527-1533. 